\title{
Investigation of Gastric Emptying Disorders in Patients with Functional Dyspepsia Reveals Impaired Inhibitory Gastric Emptying Regulation in the Early Postcibal Period
}

\author{
Hiroaki Zai $^{a}$ Motoyasu Kusano ${ }^{b}$ \\ aDepartment of Medicine and Molecular Science, Gunma University Graduate School of Medicine, and \\ ${ }^{b}$ Department of Endoscopy and Endoscopic Surgery, Gunma University Hospital, Maebashi, Japan
}

\section{Key Words}

Accelerated gastric emptying $\cdot$ Impaired inhibitory gastric regulation $\cdot$ Intestinal overload $\cdot{ }^{13} \mathrm{C}$ breath test

\begin{abstract}
Background/Aims: The aim of the study was to investigate gastric emptying profiles in patients with postprandial distress syndrome (PDS) as a means to understand relationships between gastric emptying and dyspepsia. Methods: Gastric emptying times were measured using a ${ }^{13} \mathrm{C}$ breath test. In addition to comparisons of ${ }^{13} \mathrm{C}$ half excretion times ( $\mathrm{t}$ $1 / 2$ ex) between patients with PDS and healthy subjects, gastric emptying (\%dose/h) curves were analyzed using a multipeak curve-fitting technique, and fitted curves were differentiated to measure the slope of curves for each time point. Results: (1) During the early postcibal period, the slope of $\%$ dose/h curves in $27 \%$ of patients with PDS was larger than the average slope derived from healthy subjects. The $t / 2 \mathrm{ex}$ was also higher in these patients relative to healthy subjects. (2) During the midpostcibal period, the slope of \%dose/h curves in $36 \%$ of PDS patients was larger than the average slope derived from healthy subjects. There was a trend toward lower $t 1 / 2$ ex values for these patients relative to control subjects. (3) When t 1/2 ex was calculated overall, however, there was no significant difference between healthy
\end{abstract}

subjects and patients with PDS. Conclusion: Our findings document abnormal gastric outflow in patients with PDS. In some patients, there appears to be a significant correspondence between PDS-related dyspepsia and accelerated gastric emptying in the early postcibal period, whereas other patients showed a similar correspondence between dyspepsia and impaired inhibitory gastric emptying regulation in the midpostcibal period.

Copyright $\odot 2009$ S. Karger AG, Basel

\section{Introduction}

Although a better understanding of gastric emptying and motility was achieved during investigations of the pathogenesis of nonulcer dyspepsia or functional dyspepsia (FD) [1-7], the relationship between dyspepsia symptoms and abnormal gastric emptying remains poorly understood.

'Delayed gastric emptying' was initially assumed to be the main etiology of symptoms in FD. However, mandatory acceleration of delayed gastric emptying by prokinetic agents has been shown to have little efficacy in improving dyspepsia in patients with FD [8]. This finding influenced research in functional gastrointestinal disorders greatly, providing an important clue that questioned 


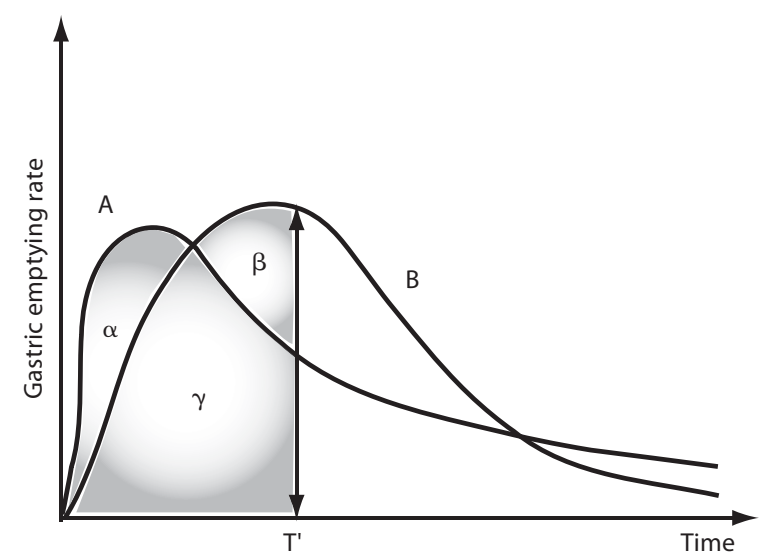

Fig. 1. Pitfalls in the measurement of gastric emptying. $t / 2$ is the time at which half the ingested volume has been discharged from the stomach. Ingested volume is calculated by integrating the area under the curve of time points taken during measurements of the gastric emptying rate. In $\mathrm{A}$ or $\mathrm{B}$, the volume excreted at $\mathrm{T}$ ' is determined by the area of ' $\alpha+\gamma$ ' or ' $\beta+\gamma$ ', respectively. If the area of $\alpha$ is equal to $\beta$ at T', the volume excreted from the stomach is identical in both cases. Because the time at T' equals the time at $\mathrm{t}$ $1 / 2$ in some cases, gastric emptying is considered equivalent in these 2 cases, although there are clearly differences in rate within the measured time period.

the physiological mechanism behind delayed gastric emptying and leading to the hypothesis that delayed emptying occurred in response to other disorders in the gastrointestinal regulatory system.

Many clinical studies involving measurements of gastric emptying use half emptying time (t $1 / 2)$ as a parameter for evaluating gastric function, despite the fact that identical $t 1 / 2$ values may not necessarily correspond to the same extent of gastric emptying (fig. 1). Single-point parameters such as $t 1 / 2$ are limited in that they cannot depict dynamic changes in gastric emptying. The aim of this study was to measure changes in gastric emptying velocity continuously in order to obtain a more comprehensive understanding of gastric emptying dynamics in healthy adults as well as in patients with postprandial distress syndrome (PDS).

\section{Subjects and Methods}

\section{Subjects}

Twenty-three healthy volunteers and 11 patients with PDS, but without Helicobacter pylori infection, were recruited. The following inclusion criteria were applied: (1) no previous abdominal sur- gery (except appendectomy), (2) no regular medications and (3) no intake of medications during the previous week that could alter gastrointestinal motor function.

\section{Experimental Protocol}

All examinations were performed after an overnight fast (the subjects could drink water freely until 30 min before examination). All subjects ingested the test meal within the first 3 min of the examination and then lay in a supine position during the examination. The Institutional Review Board of the Gunma University Graduate School of Medicine approved the study protocol and all subjects gave written informed consent.

\section{Test Meals}

The liquid test meal (400 kcal in $400 \mathrm{ml} \mathrm{K3-S;} \mathrm{Kewpie} \mathrm{Corpo-}$ ration, Tokyo, Japan), consisting of $64.4 \%$ carbohydrate, $17.6 \%$ fat and $18 \%$ protein, was labeled with $100 \mathrm{mg}{ }^{1-13} \mathrm{C}$ sodium acetate (Cambridge Isotope Laboratories Inc., Cambridge, Mass., USA).

\section{Measurement of Gastric Emptying}

A continuous ${ }^{13} \mathrm{C}$ breath test (Breath ID System; Exalenz Bioscience Ltd., Modiin, Israel) was performed. Breath samples were obtained automatically and continuously through an exclusive nasal cannula for $4 \mathrm{~h}$ after ingestion of the test meal. The total number of breaths sampled ranged between 90 and 100 .

\section{Data Analysis}

Gastric emptying was evaluated from half excretion time $(\mathrm{t} 1 / 2$ ex; reflecting $t$ 1/2) as defined by Ghoos and coworkers [9-11]. In addition, slopes of gastric emptying curves (\%dose/h curve) were also determined. To analyze gastric emptying profiles, \%dose/h curves were analyzed by fitting data to a curve using nonlinear regression analysis (Gauss-Newton method) [12-16]. The fitted curves were derived from the sum of 2 or more Gaussian components. Convergence to a curve was judged as fit when the percentage of change of the residual sum of squares was less than $0.01 \%$ and the value of the residual sum of squares was less than 15.00. Differentiation was used to calculate the slope of each curve at each time point. Analyses were performed using Igor Pro, version 4.09J (WaveMetrics Inc., Lake Oswego, Oreg., USA).

\section{Statistical Analysis}

Results were expressed as means \pm SD. Student t tests were performed to compare means, and statistical significance was defined by a $p$ value $<0.05$.

\section{Results}

\section{Three PDS Cases Demonstrated Accelerated Gastric}

Emptying during the Early Postcibal Period

In 3 of 11 patients (27\%), the slope of the \%dose/h curve was greater than the mean slope value $(+1 \mathrm{SD})$ for 23 healthy subjects $(19.79 \pm 7.15)$ during the early postcibal period (table 1). Figure 2 shows the gastric emptying profiles of these 3 PDS patients, who all demonstrated $\%$ dose/h curves that ascended steeply relative to healthy 


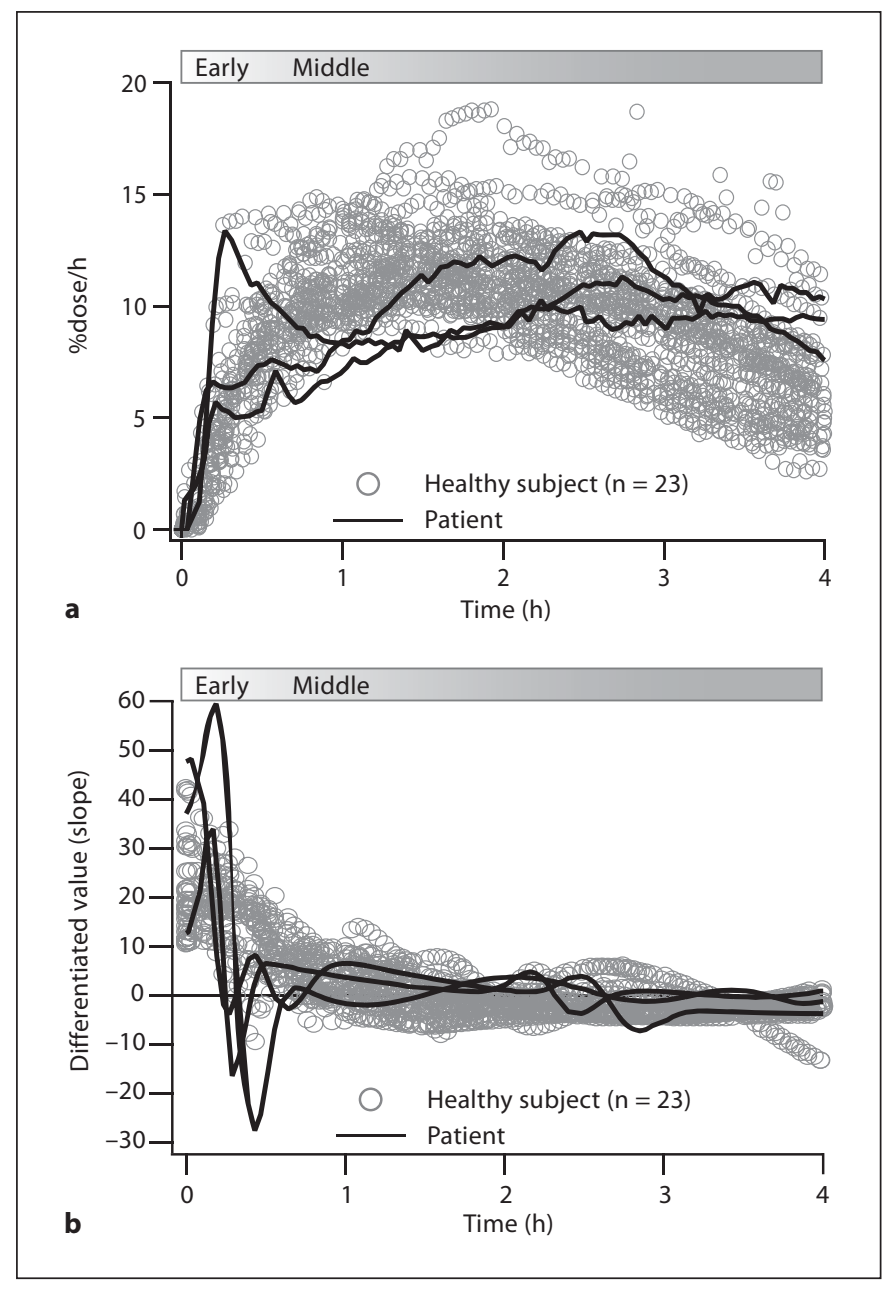

Fig. 2. Abnormal gastric emptying profiles in PDS during the early postcibal period. a Rapid gastric emptying. Each PDS patient's $\%$ dose/h curve ascended more steeply than the average of healthy subjects in the very early postcibal period. Interestingly, the slopes of the curves in these 3 patients were lower than healthy subjects in the subsequent period. b Differentiated value (slope) of \%dose/h curves. In 3 patients with PDS, the slopes of differentiated curves remained higher than healthy subjects in the very early postcibal period, and then appeared to shift in a downward direction relative to healthy subjects.

subjects (open circles; fig. $2 a$ ). The $t 1 / 2$ ex in 2 of these 3 patients was greater than the average of $t / 2 \mathrm{ex}(+2 \mathrm{SD})$ of the healthy subjects $(3.70 \pm 0.63 \mathrm{~h}$; table 1$)$. These results suggested that accelerated gastric emptying in the very early postcibal period occurred in approximately one quarter of PDS patients with delayed gastric emptying. Changes in slope values (differentiated \%dose/h curves) are shown in figure $2 \mathrm{~b}$. The differentiated values in 3 patients, which were higher than the healthy subject

Gastric Emptying Disorders in PDS
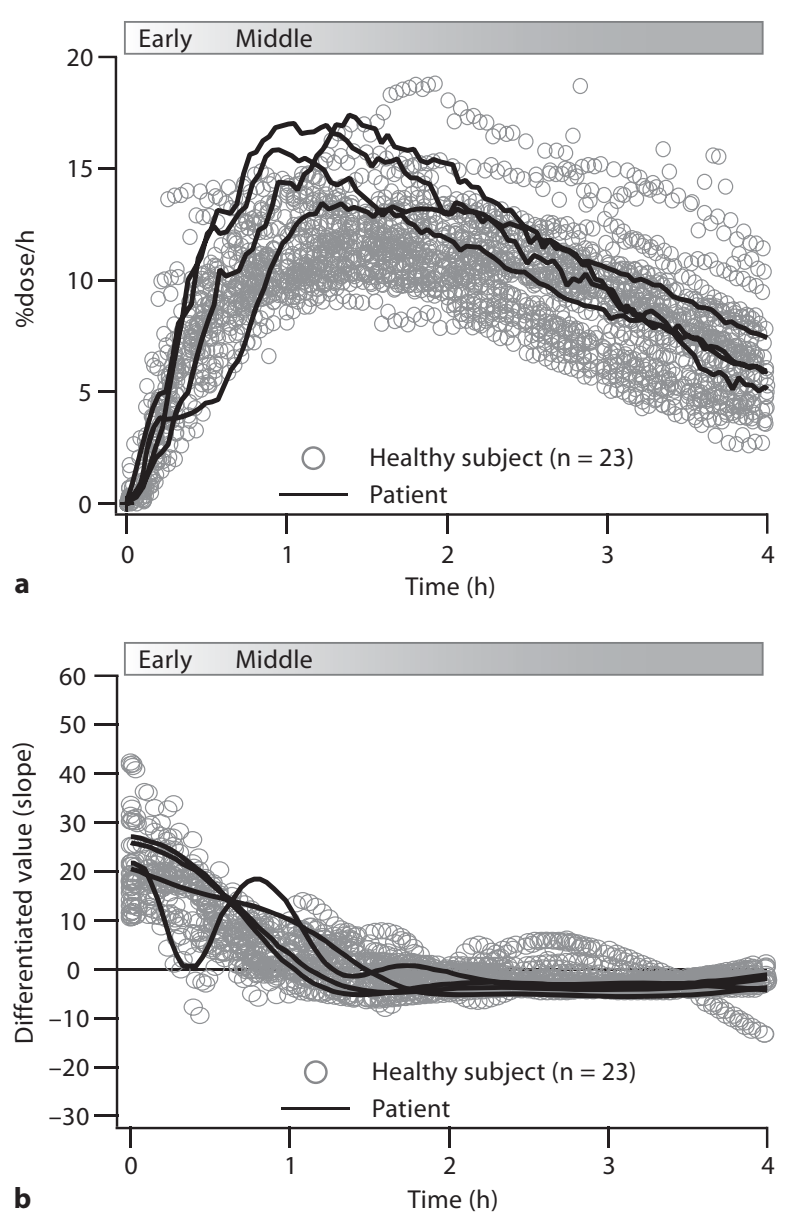

Fig. 3. Abnormal gastric emptying profiles in PDS during the midpostcibal period. a Rapid gastric emptying. The slopes of $\%$ dose/h curves in 4 PDS patients were greater than those of healthy subjects during the midpostcibal period. b Differentiated value (slope) of \%dose/h curves. In 4 patients with PDS, the differentiated curves remained higher at the beginning of the midpostcibal period relative to healthy subjects.

average during the first $15 \mathrm{~min}$ of the experiment, showed a significant dip below the average slope of healthy subjects (open circles) immediately thereafter (approximately $30 \mathrm{~min})$.

\section{Four PDS Cases Demonstrated Accelerated Gastric}

Emptying during the Midpostcibal Period

The gastric emptying profiles of 4 patients with PDS (36\%) are shown in figure 3 a. Relative to the \%dose/h 
Table 1. The slope of \%dose/h curves and gastric emptying

\begin{tabular}{llll}
\hline & Early postcibal period & Midpostcibal period & $\mathrm{t} 1 / 2 \mathrm{ex}, \mathrm{h}$ \\
\hline Healthy subjects $(\mathrm{n}=23)$ & $19.79 \pm 7.15$ & $4.68 \pm 2.52$ & $3.70 \pm 0.63$ \\
\hline Rapid GE in the early postcibal period & & \\
Case 1 & $27.19(>19.79+7.15)$ & 2.24 & $7.12^{\mathrm{a}}$ \\
Case 2 & $34.19(>19.79+7.15)$ & 2.93 & 4.25 \\
Case 3 & $52.78(>19.79+7.15)$ & -0.49 & $26.64^{\mathrm{a}}$ \\
\hline Rapid GE in the midpostcibal period & $10.01(>4.68+2.52)$ & $2.12^{\mathrm{b}}$ \\
Case 1 & 14.42 & $8.34(>4.68+2.52)$ & $2.15^{\mathrm{b}}$ \\
Case 2 & 22.98 & $9.25(>4.68+2.52)$ & $2.12^{\mathrm{b}}$ \\
Case 3 & $9.56(>4.68+2.52)$ & 2.71 \\
Case 4 & 23.06 & & \\
\hline \multicolumn{4}{l}{ GE $=$ Gastric emptying. } \\
a Above healthy subject average +2 SD. ${ }^{\mathrm{b}}$ Below healthy subject average -2 SD.
\end{tabular}

curves of healthy subjects (open circles), the curves for these 4 patients were somewhat elevated in the midpostcibal period. The slope of the \%dose/h curve in each of these 4 patients was greater than the average slope ( $+1 \mathrm{SD})$ of healthy subjects $(4.68 \pm 2.52$; table 1$)$, whereas the $1 / 2$ ex for 3 of these 4 patients was smaller than the average $(-2 \mathrm{SD}) \mathrm{t} 1 / 2$ ex in healthy subjects $(3.70 \pm 0.63 \mathrm{~h}$; table 1$)$.

These results suggest that accelerated gastric emptying specifically during the midpostcibal period occurred in a portion of PDS patients. Differences in slope are shown in figure $3 \mathrm{~b}$. At the beginning of the midpostcibal period, the differentiated \%dose/h curves (slope of $\%$ dose/h curves) for healthy subjects (open circles) shifted downward gradually, indicating a decrease in the rate of gastric emptying; in contrast, the slopes of these curves remained elevated in the 4 patients with PDS. These results provide evidence for impaired inhibitory gastric regulation in the midpostcibal period.

\section{Evaluation of Gastric Emptying based on 1 1/2 ex}

Despite the dynamic changes observed in the \%dose/h curves described above, there was no significant difference between mean $\mathrm{t} 1 / 2$ ex values for 11 patients with $\mathrm{FD}$ $(3.47 \pm 1.66 \mathrm{~h})$ relative to 23 healthy subjects $(3.70 \pm$ $0.63)$. This result indicates that, relative to multipoint dynamic analyses, comparisons of single-parameter measures of gastric emptying (t 1/2 ex) are more limited in their sensitivity of detecting altered patterns of emptying.

\section{Discussion}

The physiological role of gastric accommodation, which may relate to the symptoms of patients with FD, has been a recent focus of research attention [17-20]. During the early postcibal period, gastric accommodation in response to the stimulus of ingestion may set the appropriate conditions for gastric contraction and emptying. According to Tack et al. [20], approximately $15 \mathrm{~min}$ are required for maximum gastric relaxation to occur after intake of a liquid test meal $(300 \mathrm{kcal} / 200 \mathrm{ml})$. In this report, the authors not only suggested the value of continuous examination of gastric emptying, particularly before and after gastric accommodation in the early postcibal period, but also predicted that a single parameter (such as $t 1 / 2$ ) would be incapable of demonstrating dynamic changes in gastric emptying velocity. The data presented in our study, which investigated the time course of gastric emptying, demonstrate that dynamic changes in gastric outflow occur at an early postprandial stage.

Subgroups of PDS patients demonstrated 1 of 2 characteristic times of abnormal gastric outflow during exponential gastric emptying, either in the very early postcibal period or in the midpostcibal period. Among those with alterations during the very early postcibal period, we noted a correspondence between exponential rates of gastric emptying and overall delays in gastric emptying. Although the cause of exponential gastric emptying was unclear, we predict that expulsion of a high-osmolarity liquid meal not adequately diluted by gastric juices into the duodenum can result in strong inhibition of gastric emptying. Receptors in the duodenum that respond to 
osmotic changes in chyme may be particularly important in regulating rapid emptying of liquids during the very early postcibal period, before other regulatory mechanisms are fully operational [21].

The inhibitory effect of nutrients in the duodenum on gastric emptying can be long lasting [22]. It has been suggested that impaired gastric accommodation, or antropyloro dysmotility, in patients with PDS relates to excessive gastric outflow in the very early postcibal period, which then results in delayed gastric emptying. Accelerated gastric emptying in the early postprandial period has also been reported by Kindt et al. [23]. Thus, it appears that delayed gastric emptying may be induced not only by gastric dysmotility, but also by too rapid gastric emptying in the very early postcibal period.

The other subgroup of PDS patients showed rapid gastric emptying during the midpostcibal period. Since undiluted gastric contents have a composition that is poorly tolerated by the duodenum, inhibitory regulation of gastric emptying is necessary during this period to adjust for differences in the intraluminal milieu of the small intestine versus that of the stomach. Regulation of gastric emptying compensates for minute-to-minute variations in the volume, composition and physical state of the duodenum.

Although rapid gastric emptying in patients with FD has not previously been a focus of attention, analyses of abnormal gastric emptying profiles during each postcibal period are necessary to elucidate relationships between gastric emptying and dyspepsia. Orderly delivery of gastric chyme to the duodenum at a rate that does not cause overload is essential for maximizing the digestive and absorptive functions of the small intestine. When calorie overload does occur in the intestine, symptoms similar to those during dumping syndrome result.

Previous studies investigating the effect of prokinetic agents on dyspeptic symptoms associated with delayed gastric emptying reported the inefficacy of such medications $[8,24,25]$. One reason for these results may be that dyspeptic symptoms are the direct result of abnormal gastric emptying or gastric dysmotility, and not impaired regulation of gastric emptying. In other words, whereas no dyspeptic symptoms occur during the process of digestion and absorption during normal gastric emptying, dyspeptic symptoms result when the stomach and intestine cannot adequately adapt to various external stimuli, including certain nutrients, food intake per se or psychological stress.

According to Rome III diagnosis criteria, epigastric pain syndrome is closely related to gastric acid [26, 27].
Epigastric pain syndrome symptoms, which include unrecognized gastroesophageal reflux disease, but not mealrelated symptoms, have been shown to respond to proton pump inhibitors. In contrast, the wide variety of pathophysiological problems involved with dyspepsia in PDS has promoted controversy in determining effective therapeutics for PDS. Because an effective response to acid inhibitors eliminates the etiology of dyspepsia caused by gastric acid, preliminary administration of these agents can clarify the etiology of PDS. We therefore propose a two-step therapeutic path for treatment of FD as follows: (1) administer an acid inhibitor to evaluate the influence of gastric acid and (2) if the acid inhibitor is not efficacious, investigate the gastric emptying profile for abnormalities. On-demand administration of prokinetics or anticholinergic drugs should be tried for adjusting the delivery of gastric chyme to an optimal rate for the small intestine.

In conclusion, this report presents data identifying abnormal gastric emptying profiles by detailed analysis of the slope of \%dose/h curves in patients with PDS. These data suggest that some patients with PDS may be impaired in orderly delivery of gastric chyme to the duodenum and that such disorders could lead to dyspeptic symptoms.

\section{Acknowledgement}

We especially thank Dr. Zen Itoh, Professor Emeritus of Gunma University, for his general supervision, technical help and writing assistance.

\section{Disclosure Statement}

The author declares that no financial or other conflict of interest exists in relation to the content of the article. 


\section{References}

1 Non-ulcer dyspepsia. Lancet 1986;ii:113.

$\checkmark 2$ Brown GM, Purchase EC, Bresnahan TJ: Nocturnal gastric contents in duodenal ulcer and non-ulcer dyspepsia; studies of volume, acidity and peptic activity. Gastroenterology 1952;21:331-338.

3 Roberts DM: Chronic gastritis, alcohol, and non-ulcer dyspepsia. Gut 1972;13:768-774.

4 Talley NJ, Piper DW: The association between non-ulcer dyspepsia and other gastrointestinal disorders. Scand J Gastroenterol 1985;20:896-900.

5 Camilleri M, Thompson DG, Malagelada JR: Functional dyspepsia. Symptoms and underlying mechanism. J Clin Gastroenterol 1986; 8:424-429.

-6 Greydanus MP, Vassallo M, Camilleri M, Nelson DK, Hanson RB, Thomforde GM: Neurohormonal factors in functional dyspepsia: insights on pathophysiological mechanisms. Gastroenterology 1991;100:13111318.

7 Malagelada JR: Gastrointestinal motor disturbances in functional dyspepsia. Scand J Gastroenterol Suppl 1991;182:29-32.

8 Talley NJ, Verlinden M, Snape W, Beker JA, Ducrotte P, Dettmer A, Brinkhoff H, Eaker E, Ohning G, Miner PB, Mathias JR, Fumagalli I, Staessen D, Mack RJ: Failure of a motilin receptor agonist (abt-229) to relieve the symptoms of functional dyspepsia in patients with and without delayed gastric emptying: a randomized double-blind placebo-controlled trial. Aliment Pharmacol Ther 2000;14:1653-1661. $\checkmark 9$ Ghoos YF, Maes BD, Geypens BJ, Mys G, Hiele MI, Rutgeerts PJ, Vantrappen G: Measurement of gastric emptying rate of solids by means of a carbon-labeled octanoic acid breath test. Gastroenterology 1993;104: 1640-1647.

10 Maes BD, Ghoos YF, Hiele MI, Rutgeerts PJ: Gastric emptying rate of solids in patients with nonulcer dyspepsia. Dig Dis Sci 1997; 42:1158-1162.

11 Maes BD, Ghoos YF, Rutgeerts PJ, Hiele MI, Geypens B, Vantrappen G: $\left[{ }^{*} \mathrm{C}\right]$ octanoic acid breath test to measure gastric emptying rate of solids. Dig Dis Sci 1994;39:104S-106S.

12 Amisaki T: Gaussian quadrature as a numerical integration method for estimating area under the curve. Biol Pharm Bull 2001;24: 70-77.

13 Matthews HR: A curve analyzer for microcomputers. Comput Methods Programs Biomed 1985;20:261-267.

14 McIsaac RL, Johnston BJ, Flannery MC: Dose-response curve analysis of gastric secretory responses in the dog and man to impromidine: a new histamine-H2-receptor agonist. J Pharmacol Exp Ther 1983;225: 186-190.

15 Motulsky HJ, Ransnas LA: Fitting curves to data using nonlinear regression: a practical and nonmathematical review. FASEB J 1987; 1:365-374.

16 Shi JQ, Wang B, Murray-Smith R, Titterington DM: Gaussian process functional regression modeling for batch data. Biometrics 2007;63:714-723.

17 Tack J: Functional dyspepsia: impaired fundic accommodation. Curr Treat Options Gastroenterol 2000;3:287-294.

18 Tack J: The physiology and the pathophysiology of the gastric accommodation reflex in man. Verh K Acad Geneeskd Belg 2000;62: 183-207; discussion 207-110.
19 Tack J, Demedts I, Meulemans A, Schuurkes J, Janssens J: Role of nitric oxide in the gastric accommodation reflex and in meal induced satiety in humans. Gut 2002;51:219-224.

20 Tack J, Piessevaux H, Coulie B, Caenepeel P, Janssens J: Role of impaired gastric accommodation to a meal in functional dyspepsia. Gastroenterology 1998;115:1346-1352.

21 Houpt TR, Houpt KA, Swan AA: Duodenal osmoconcentration and food intake in pigs after ingestion of hypertonic nutrients. Am J Physiol 1983;245:R181-R189.

22 Barker GR, Cochrane GM, Corbett GA, Hunt JN, Roberts SK: Actions of glucose and potassium chloride on osmoreceptors slowing gastric emptying. J Physiol 1974;237:183186.

23 Kindt S, Tack J: Impaired gastric accommodation and its role in dyspepsia. Gut 2006;55: 1685-1691.

24 Bytzer $\mathrm{P}: \mathrm{H}_{2}$ receptor antagonists and prokinetics in dyspepsia: a critical review. Gut 2002;50(suppl 4):iv58-iv62.

-25 Bytzer P, Moller J, Schaffalitzky de Muckadell O: Treatment of non-ulcer dyspepsia: are prokinetics effective? Scand J Gastroenterol 2002;37:617-618; author reply 618620

26 Camilleri M, Bueno L, de Ponti F, Fioramonti J, Lydiard RB, Tack J: Pharmacological and pharmacokinetic aspects of functional gastrointestinal disorders. Gastroenterology 2006;130:1421-1434.

27 Tack J, Talley NJ, Camilleri M, Holtmann G, $\mathrm{Hu}$ P, Malagelada JR, Stanghellini V: Functional gastroduodenal disorders. Gastroenterology 2006;130:1466-1479. 